\title{
VARIANCES OF DIRECT AND MATERNAL GENETIC EFFECTS FOR MILK YIELD AND ITS COMPOSITION IN A HERD OF FRIESIAN COWS IN EGYPT \\ Mostafa, M. A. ${ }^{1}$; Enas A. Bader ${ }^{2}$ and A. S. khattab ${ }^{3}$ \\ 1 Animal Production Department, Faculty of Agriculture, Mansoura University, ${ }^{2}$ Animal Production Research Institute, Ministry of Agriculture, Dokki, Cairo, ${ }^{3}$ Animal Production Department, Faculty of Agriculture, Tanta Univ., Egypt
}

\begin{abstract}
A total of 3748 normal lactation records of Friesian cows kept at Sakha farm, belonging to Animal Production Research Institute, Ministry of Agriculture, Dokki, Cairo, Egypt during the period from 2000 to 2006 were used in the present study. Data was analyzed by using Multiple Traits Derivative Free Restricted Maximum Likelihood (MTDFREML) according to Boldman et al. (1995) using repeatability animal model. Two models were used. Model 1 includes month and year of calving and parity as fixed effects and direct genetic, maternal genetic, covariance between direct and maternal genetic and residual as random effects. Model 2 is similar to Model1, while additive maternal and covariance between direct and maternal effects were omitted from the model.

Estimates of heritability for 305 day milk yield, lactation period, fat \% and protein $\%$ were $0.33,0.02,0.16$ and 0.64 , respectively for model 1 , while the values were $0.34,0.03,0.17$ and 0.65 , respectively as estimated from model 2 . The removal of additive maternal genetic effects and covariance between direct and maternal genetic effects from the model increased estimates for heritability of additive genetic effects by 0.01 , for the four traits. Therefore, the additive maternal genetic effect and covariance between direct and maternal genetic effects do not seem to make important contributions to the phenotypic variance for milk yield and it's composition.

Keyword: Friesian cows, direct and maternal genetic effects, heritability and milk traits
\end{abstract}

\section{INTRODUCTION}

Maternal effects have been defined as any influence from a dam on it is offspring, excluding the effects of directly transmitted genes that affect performance of the offspring (Legates, 1972). In mammals, environmental variation in the offspring is partially due to genetic variation of some other traits from the dams, such that quantitative traits can be influenced by two genetic components, animal genotype (direct genetic effect) and dam genotype (maternal genetic effects). The maternal genetic effects are not important for yield traits of dairy cattle (Schutz et al., 1992 ; Albuquerque et al., 1998 and Khattab et al., 2005). Khattab et al. (2005) with 2095 lactation records of Friesian cows in Egypt, found that means estimates of the effects of maternal genetic variances and direct- maternal covariances as a fractions of phenotypic variances for $305 \mathrm{~d}$ MY were 0.01 and 0.02 , respectively. The objectives of the present study were to quantify the contribution of additive direct and maternal genetic effects to phenotypic variance of milk yield and milk composition in a herd of Friesian cows in Egypt. 


\section{Source of data}

\section{MATERIALS AND METHODS}

Data used in the present study were collected from the history sheets of Friesian cows maintained at Sakha Farm, belonging to Animal production research Institute, Ministry of Agriculture, Dokki, Cairo, Egypt. The data comprised 3748 normal lactation records spread over the period from 2000 to 2006, representing in parities from 1 to 6 . Abnormal records of cows affected by diseases such as mastitis and udder troubles or reproductive disorders were excluded. Animals were grazed on Egyptian clover (Trifolium alexandrinam), berseem, during December to May. They were fed concentrate mixture along with wheat or rice straw and limited amount of clover hay when available during the rest of the year. Cows producing more than $10 \mathrm{~kg}$ a day and cow a pregnant in the last two months were supplemented with extra concentrate. Heifers were first inseminated at 18 months of age. In subsequent lactations, cows were initially inseminated 6070 days postpartum. Cows were machined twice a day. Sires which had 5 daughters or more were included in the genetic analysis. Cows were artificially inseminated randomly to ensure that no specific sires were bred to certain good or poor dams. Traits studied are 305 day milk yield, lactation period, fat \% and protein \%.Fat and protein percentages estimated using system of Milko - Scan 130 series. Type 10900.

\section{Analysis}

The records were analyzed by Multiple Trait Derivative Free Restricted Maximum Likelihood (MTDFREML) according to Boldman et al. (1995), using repeatability animal model. Two models were used, Model 1 , includes month of calving, year of calving and parity as fixed effects and direct genetic, maternal genetic, covariance between direct and maternal genetic, permanent environmental and residual as random effects. Model 2 is similar to Model 1, but excluding additive maternal and covariance between additive direct and maternal effects. Table 1 shows the data structure considered in the analysis.

Table 1. Structure of data used in analysis, means, standard deviation (SD) and coefficient of variability (CV \%) for 305-day milk yield (305-d-MY), lactation period (LP), fat (F\%) and protein (P\%).

\begin{tabular}{|l|c|c|c|}
\hline \multicolumn{1}{|c|}{ Traits } & Mean & SD & CV\% \\
\hline $\mathbf{3 0 5 - d - M Y , ~ k g ~}$ & 3558 & 1423 & 40.0 \\
\hline LP, d & 301 & 172 & 57.1 \\
\hline $\mathbf{F} \%$ & 3.7 & 0.82 & 22.2 \\
\hline $\mathbf{P \%}$ & 2.6 & 0.51 & 19.6 \\
\hline Observations & & & \\
\hline No. of records & 3748 & & \\
\hline No. of sires & 50 & & \\
\hline No. of cows & 428 & & \\
\hline No. of dams & 191 & & \\
\hline Animals in relationship matrix (A ${ }^{-1)}$ & 669 & & \\
\hline Mixed Model Equations (MME) & 5460 & & \\
\hline No. of iterations & 11789 & & \\
\hline
\end{tabular}




\section{RESULTS AND DISCUSSION}

Means of $305 \mathrm{~d}$ MY, LP, F \% and P \% , standard deviations (SD) and coefficients of variability (CV \%) are presented in table 1 . Means of $305 \mathrm{~d}$ MY, LP, F \% and P \% were $3558 \mathrm{~kg}, 301 \mathrm{~d}, 3.7 \%$ and $2.6 \%$ (Table 1). The present means of $305 \mathrm{~d}$ MY and LP were higher than those found by Yener et al. (2006) working on another set of Friesian cows in Egypt, reported that means of $305 \mathrm{~d}$ MY and LP were $2806 \mathrm{~kg}$ and $293 \mathrm{~d}$, respectively. While the present means were lower than those reported by Khattab and Atil (1999) working on another set of Friesian cows in Egypt, found that means of $305 \mathrm{~d}$ MY and LP were $3709 \mathrm{~kg}$ and $367 \mathrm{~d}$, respectively. Overall mean of $\mathrm{F} \%$ was similar to that reported by Albuquerque et al. (1998) (3.7) working on Holstein Friesian. While The present mean of $\mathrm{F} \%$ was lower than those found by Islam et al.(2008) (4.28\%). The overall mean of $\mathrm{P} \%$ was lower than those reported by Jairath et al. (1995) (3.15) on Canadian Holstein and Islam et al. (2008) (3.11) on Holstein Friesian. The difference between the present estimates and those reported by other studied could be due to differences in climatic and management. Herds could be possibly the genetically different or be caused by different models used.

The large CV \% value for 305 d MY (40\%) reflects a great variation between individuals in such an important productive trait.

Variance components and means for variance and covariance components as ratio of phenotypic variances from model 1 and 2 are in Table 2.

Table 2. Phenotypic and genetic variance and covariance for 305-day milk yield (305-d- MY), lactation period (LP), fat percent (F\%) and protein percent $(\mathrm{P} \%)$ using two models

\begin{tabular}{|l|c|c|c|c|c|}
\hline \multicolumn{1}{|c|}{ Models } & \multicolumn{1}{c|}{$\mathbf{g}^{\mathbf{2}}$} & $\mathbf{m}^{\mathbf{2}}$ & $\mathbf{g m}$ & $\mathbf{e}^{\mathbf{2}}$ & Total \\
\hline Model 1 & & & & & \\
\hline $\mathbf{3 0 5 - d - M Y}$ & $25.52(0.33)$ & $2.91(0.04)$ & $-0.58(0.007)$ & $49.82(0.64)$ & 77.67 \\
\hline $\mathbf{L P}$ & $2.58(0.02)$ & $1.80(0.02)$ & $-0.02(0.001)$ & $113.5(0.96)$ & 117.8 \\
\hline F\% & $4.71(0.16)$ & $1.41(0.05)$ & $-0.36(0.01)$ & $24.14(0.81)$ & 29.90 \\
\hline P\% & $9.40(0.64)$ & $0.98(0.07)$ & $-0.26(0.02)$ & $4.47(0.31)$ & 14.59 \\
\hline Model 2 & & & & & \\
\hline $\mathbf{3 0 5 - d - M Y}$ & $26.40(0.34)$ & & & $50.20(0.66)$ & 76.60 \\
\hline LP & $3.10(0.03)$ & & & $114.5(0.97)$ & 117.6 \\
\hline F\% & $5.10(0.17)$ & & & $25.10(0.83$ & 30.20 \\
\hline P\% & $11.20(0.65)$ & & & $5.90(0.35)$ & 17.10 \\
\hline
\end{tabular}

*: Estimates of heritability (values between brackets) , genetic and phenotypic variance were calculated according to models 1 and 2 .

g2= additive genetic effect, $\mathrm{m}^{2}=$ additive maternal genetic effect, $\mathrm{gm}=$ covariance between direct and maternal, and $\mathrm{e}^{2}=$ residual.

The variance for additive maternal genetic effects were 4, 2, 5 and 7 $\%$ of phenotypic variance for $305-\mathrm{d}-\mathrm{MY}, \mathrm{LP}, \mathrm{F} \%$ and $\mathrm{P} \%$, respectively and the covariance between maternal and direct genetic effects were $0.07,0.01$, 
1 and $2 \%$ for the same traits respectively. Thus, these effects did not contribute importantly to phenotypic variance. Similar results were obtained by Albuquerque et al. (1998) analysis milk traits ( milk, fat yield and fat \%) reported that the variance of additive maternal genetic effects varied from 0.8 to $1.0 \%$ of phenotypic variance and the covariance between maternal and direct genetic effects varied from 0.7 to $2.5 \%$. Also, Schutz et al. (1992) using an animal model estimated small values for ratios of variance for maternal genetic effects to phenotypic variance for milk yield $(2.58 \%)$ and fat \% $(6.5$ $\%)$ and for covariance between maternal and direct effects for milk yield (5.99 $\%)$. In addition, Khattab et al. (2005) with another set of Friesian cows in Egypt, found that the variance for additive maternal genetic effect and covariance between maternal and direct genetic effects for $305 \mathrm{~d}$ MY were 1 and $2 \%$, respectively.

Maternal genetic effects have been described in domestic mammals such as swine (Southwood and Kennedy, 1999 ) and beef cattle (Dodenhoff et al., 1999) and represent an environmental effect on the growth of offspring from birth to weaning. However, dairy calves are separated from their dams at birth so that the influence of the dam would be only through intrauterine environmental (Albuquerque et al., 1998). In addition, uterine environmental and the maternal colostrums may also contribute to the maternal genetic effects (Khattab et al., 2005).

Heritability estimates for $305 \mathrm{~d}$ MY, LP, F \% and P \% as estimated from model 1 (Full model) are $0.33 \pm 0.02,0.02 \pm 0.01,0.16 \pm 0.04$ and $0.64 \pm 0.13$, respectively (Table 3 ), while the corresponding values as estimated from model 2 are $0.34,0.03,0.17$ and 0.65 , respectively (Table 4). The removal of additive genetic maternal effects and covariance between direct and maternal effects from the model (Model 2) increased estimates of heritability of direct genetic effects by 0.01 for all traits studied (Tables 2 and 4). Similar results are reported by Albuquerque et al. (1998) found that heritability estimates of direct genetic effects increased by $0.014,0.021$ and 0.046 for milk yield, fat yield and fat \%, respectively, when additive genetic maternal effects and covariance between direct and maternal genetic effects are removed from the analysis. The same authors also concluded that, some confounding between direct and maternal genetic effects should be expected because the dam that contributes the maternal genetic effect also transmits half of her genetic value for direct effects in her daughter. Some cows do not have lactating daughters, and many sires do not have any lactating granddaughters. Also, Schutz et al. (1992) and Khattab et al. (2005) arrived at the same conclusion, reported that maternal genetic effects are not important for yield traits of dairy cattle. 
Table 3. Estimates of heritability (direct and maternal genetic) and genetic correlations among 305-d-MY, LP, F\% and P\% as estimated from model $1^{*}$

\begin{tabular}{|l|c|c|c|c|}
\hline & $\mathbf{g}^{\mathbf{1}}$ & $\mathbf{g}^{\mathbf{2}}$ & $\mathbf{g}^{\mathbf{3}}$ & $\mathbf{g}^{\mathbf{4}}$ \\
\hline $\mathbf{g}^{\mathbf{1}}$ & $\mathbf{0 . 3 3} \pm \mathbf{0 . 0 2}$ & & & \\
\hline $\mathbf{g}^{\mathbf{2}}$ & $0.16 \pm 0.01$ & $\mathbf{0 . 0 2} \pm \mathbf{0 . 0 1}$ & & \\
\hline $\mathbf{g}^{\mathbf{3}}$ & $-0.10 \pm 0.01$ & $-0.12 \pm 0.02$ & $\mathbf{0 . 1 6} \pm \mathbf{0 . 0 4}$ & \\
\hline $\mathbf{g}^{\mathbf{4}}$ & $-0.13 \pm 0.01$ & $-0.18 \pm 0.02$ & $0.45 \pm 0.14$ & $\mathbf{0 . 6 4 \pm 0 . 1 3}$ \\
\hline
\end{tabular}

*: Estimates of heritability and genetic correlations were calculated according to model 1. 30- d-MY, LP, F\%, P\%, g1, g2, g3 and g4 are 305 day milk yield, lactation period, fat \%, protein $\%$, direct heritability for $305 \mathrm{~d}$ MY, LP, F \% and P \%, respectively.

Direct heritability estimates for 305-d-MY, LP, F\% and P\% as estimated from model 1 (full model) are $0.33,0.02,0.16$ and 0.64 , respectively (Table 3 ). The present estimates are within the range of recorded value with an animal model (i.e., Albuquerque et al., 1998; El- Arian et al., 2003; Yener et al., 2006 and Usman et al., 2012) and ranged from 0.07 to 0.0 .33 . The moderate estimates of heritability for $305 \mathrm{~d} \mathrm{MY}$ and $\mathrm{F} \%$ and high estimate of heritability for $\mathrm{P} \%$, suggests that more efforts could be made to bring about improvement milk yield and it is composition through individual selection as well as better managerial practices. Low heritability estimates for LP indicate that this trait is affected mainly by environmental factors.

The results in table 3 show that the genetic correlation from model 1 between $305 \mathrm{~d}$ MY and LP was positive and being $0.16+0.01$ and in the desirable direction indicating that high yielding cows are also have the longer LP. Whereas the genetic correlation between $305 \mathrm{~d}$ MY and each of $\mathrm{F} \%$ and $\mathrm{P} \%$ were negative and being $-0.10 \pm 0.01$ and $-0.13 \pm 0.01$, respectively. Also, the genetic correlation between LP and each of $F$ and $P \%$ were negative and being $-0.12 \pm 0.02$ and $-0.18 \pm 0.02$, respectively (Table 3 ). The present results indicated that selection for milk yield and lactation period would lead to slight decreases in fat and protein percent. While, genetic correlation between $\mathrm{F}$ and $\mathrm{P} \%$ was positive $(0.45 \pm 0.14)$. The results in table 4 show that the genetic correlations from model 2 between the same traits were in the same trend but slightly higher than the values obtained from model 1. Similar results are reported by El- Arian et al. (2003), Yener et al. (2006) and Usman et al. (2012). Also, maternal genetic correlation among milk traits studied are in most cases negative and small. 
Table 4. Estimates of direct heritability and genetic correlations among 305-d-MY, LP, F\% and P\% as estimated from model $2^{*}$

\begin{tabular}{|l|c|c|c|c|}
\hline & $\mathbf{g}^{\mathbf{1}}$ & $\mathbf{g}^{\mathbf{2}}$ & $\mathbf{g}^{\mathbf{3}}$ & $\mathbf{g}^{\mathbf{4}}$ \\
\hline $\mathbf{g}^{\mathbf{1}}$ & $0.34 \pm 0.01$ & & & \\
\hline $\mathbf{g}^{\mathbf{2}}$ & $0.54 \pm 0.06$ & $0.03 \pm 0.01$ & & \\
\hline $\mathbf{g}^{\mathbf{3}}$ & $-0.28 \pm 0.10$ & $-0.22 \pm 0.05$ & $0.19 \pm 0.05$ & \\
\hline $\mathbf{g}^{\mathbf{4}}$ & $-0.20 \pm 0.05$ & $-0.66 \pm 0.04$ & $0.42 \pm 0.16$ & $0.65 \pm 0.14$ \\
\hline
\end{tabular}

*: Estimates of heritability and genetic correlations were calculated according to model 2. g1,g2. g3 and g4 are direct heritability for 305 day milk yield ( 305 d MY), lactation period (LP), Fat \% ( F\%) and protein \% ( $\mathrm{P} \%)$, respectively.

According to small amount of additive maternal genetic effects for 305 d MY, LP, F \% and P \% (Tables 2 to 4), it could be concluded that the additive maternal genetic effects and the covariance between additive maternal and direct genetic effects do not seem to make important contributions to the phenotypic variance of milk traits, probably because the important environmental influence of the dams on their calves from conception to birth.

\section{REFERENCES}

Albuquerque, L. D.;Keown, J.F. and Van Vleck, L.D (1998). Variances of direct genetic effects, maternal genetic effects and cytoplasm inheritance effects for milk yield, fat yield and Fat percentage. J. Dairy Sci., Vol. 81: 544 - 549

Boldman, K,G.; Kriese, L.A.; Van Vleck, L.D. and Kachman, S.D.(1995). A manual for use of MTDFREML, Department of Agriculture/ Agricultural Research Service, Lincoln, $120 \mathrm{pp}$.

Dodenhoff, J.; Van Vleck, L.D. and Gregory, K.E. (1999). Estimation of direct, maternal and maternal genetic effects for weaning weight in several breeds of beef cattle. J. Anim. Sci., 77(4): 840-845.

El-Arian, M.N.; El-Awady, H.M. and Khattab, A.S. (2003). Genetic parameters and breeding values of milk production traits by using animal model in a herd of Holstein Friesian cows in Egypt. 53 $3^{\text {rd }}$ Annual Meeting of the European Association for Animal Production, Cairo, Egypt, 1-4 September.

Islam, M.R.; Hassan, M.N.; Siddiki, M.S.R.; Khan, M.A.S. and Islam, M.A. (2008). Determination of quality of milk from different genotype of dairy cows. Bangladesh. J. Anim. Sci., 37: 53.

Jairath, L.K.; Hayes, J.F. and Cue, R.I. (1995). Correlations between first lactation and lifetime performance traits of Canadian Holsteins. J. Dairy Sci., 78: 438.

Khattab, A.S. and Atil, H.(1999). Genetic study of fertility traits and productive in a local Friesian cattle in Egypt. Pakistan J. Biol., 2: 1178.

Khattab, A.S.; Atil, H. and Badawy L. (2005). Variances of direct and maternal genetic effects for milk yield and age at first calving in a herd of Friesian cattle in Egypt. Arch. Tierz. $\quad$ Dummerstorf., 48: 24-31. 
Legates, J.E. (1972). The role of maternal effects in animal breeding. IV. Maternal effects in laboratory species. J. Anim. Sci., 35: 1294 -1302.

Schutz, M.M.; Freeman, A.E.; Beitz, D.C. and Mayfield , J.E. (1992). The importance of maternal lineage on milk yield traits of dairy cattle. J. Dairy Sci., 75: 1331-1341.

Southwood, O.I. and Kennedy, B.W. (1999). Estimation of direct and maternal genetic variance for litter size in Canadian Yorkshire and Landrace Swine using an animal model. J. Anim. Sci., 68: 1841-1847.

Usman, T.; Guo, G.; Suhail, S.M. and Wang, Y. (2012). Performance traits study of Holstein Friesian cattle under subtropical conditions. J. of Animal and Plant Sci., 22:92-95.

Yener, S.M.; Akman, N.; Khattab, A.S. and Hussein, A. (2006). Genetic aspects for productive and reproductive traits for Friesian cows in Egypt. 57 $7^{\text {th }}$ Annual meeting of the European Association for Animal Production, Antalya, Turkey

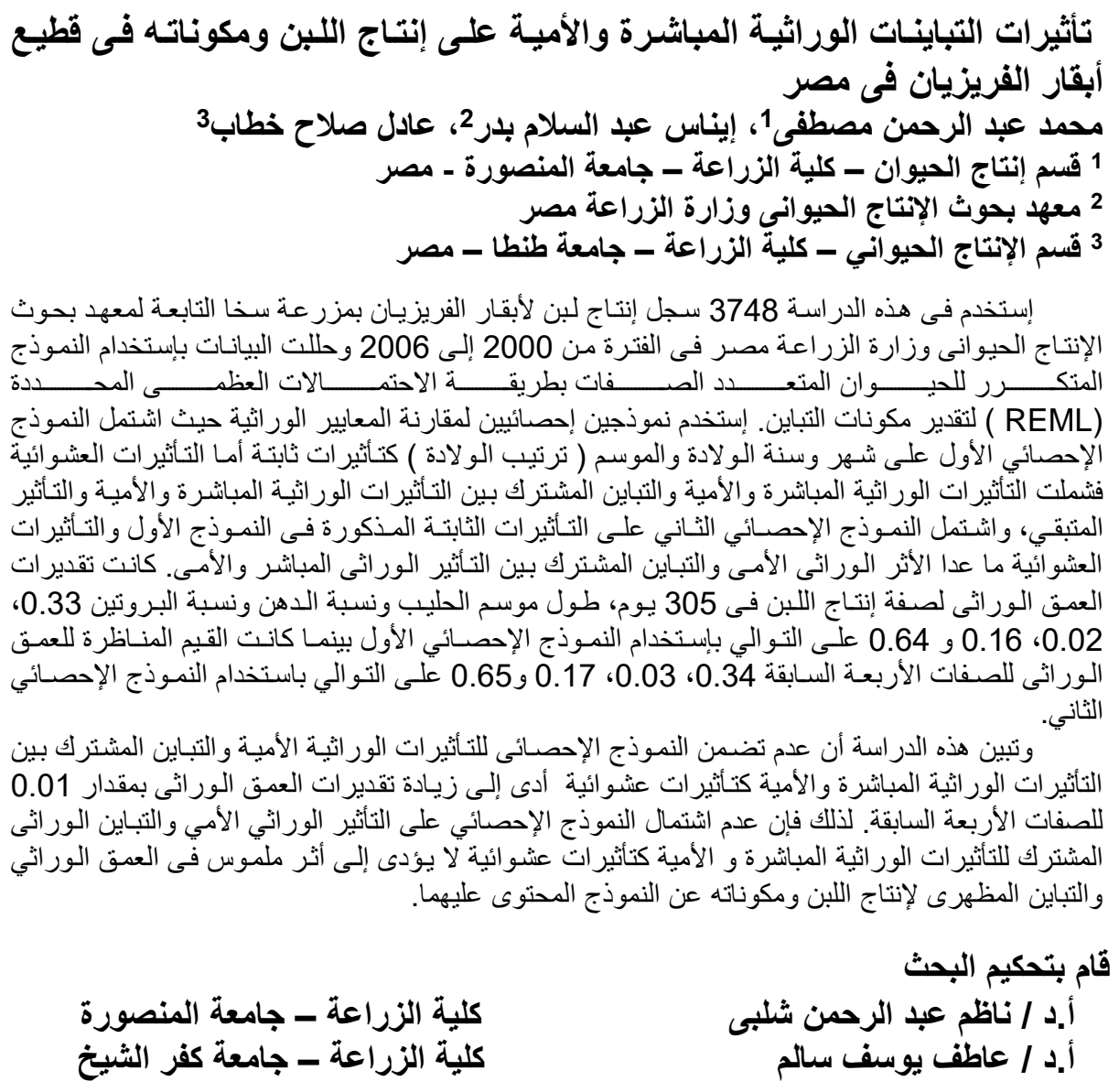

